\author{
Antonio Perciaccante \\ Alessandra Fiorentini \\ Milica Mitrevski \\ Luigi Tubani \\ Massimo Granata
}

\section{Temporary pacemaker in refractory cluster headache treated with verapamil}

Received: 6 December 2006

Accepted in revised form: 9 January 2007

Published online: 19 February 2007
Sir,

We present a 35-year-old male patient with 10 years' history of episodic cluster headache (3-4 attacks per day, previously treated with methysergide, lithium and oxygen without significant benefit). Therapy with verapamil $240 \mathrm{mg} /$ day reduced the frequency of attacks (2-3 per day). After increasing the dose of verapamil to $360 \mathrm{mg} /$ day the patient presented hypotension $(75 / 40 \mathrm{mmHg})$ and serious bradycardia (HR 32/min), which required the implant of a temporary ventricular non-sequential pacemaker. Once the critical period had passed, the blood pressure normalised; after the electrophysiology study found normal results, it was possible to remove the pacemaker. Before starting verapamil therapy, cardiac examination and 24-h ECG recording were normal.

In the last 7 years, we have been observing four patients treated with verapamil for episodic cluster headache that have referred hypotension and serious bradycardia. The patients have not presented any contraindication to prophylactic therapy with verapamil. Verapamil is a calcium channel blocker and its common adverse effects include constipation, dizziness, nausea, bradycardia and hypotension. It is widely used as a first-line prophylactic drug for cluster headache at doses starting at $360 \mathrm{mg}$ $[1,2]$. Patients with cluster headache present an increase in sympathetic tone before the attack of a headache. This "sympathetic storm" could cause short but hazardous periods of arrhythmia [3]. On the contrary, a parasympathetic overactivity with consequent bradycardia is present during the attack $[4,5]$. Verapamil therapy prevents episodic cluster headache but it requires a strict control of blood pressure and heart rate, because an overlap between the effects of verapamil and the effects of the parasympathetic overactivity characterising the attack of cluster headache that could cause serious hypotension and bradycardia can be verified [6].

\section{A. Perciaccante $\cdot$ A. Fiorentini L. Tubani Cardiology Unit,}

Department of Clinical Medicine, University of Rome "La Sapienza”, Rome, Italy

M. Mitrevski • M. Granata (凶) Headache Centre, Department of Clinical Medicine, University of Rome "La Sapienza", Rome, Italy

e-mail: massimo.granata@uniromal.it 


\section{References}

1. Favier I, Haan J, Ferrari MD (2005) Chronic cluster headache: a review. J Headache Pain 6:3-9

2. Dousset V, Chrysostone V, Ruiz B et al (2004) Does repeated subcutaneous administration of sumatriptan produce an unfavorable evolution in cluster headache? J Headache Pain 5:110-114
3. De Marinis M, Strano S, Granata M et al (1996) Spectral analysis of heart-rate fluctuation in cluster headache.

Cephalalgia 16:357

4. Gouveia RG, Parreira E, Martins IP (2005) Autonomic features in cluster headache. Exploratory factor analysis. J Headache Pain 6:20-23
5. De Marinis M, Strano S, Granata M et al (1995) Sympathetic-parasympathetic activation during spontaneous attacks of cluster headache: evaluation by spectral analysis of heart-rate fluctuations. Cephalalgia 15:504-510

6. Barrow PM, Houston PL, Wong DT (1994) Overdose of sustained-release verapamil. Br J Anaesth 72:361-365 